\title{
Uniformidade de distribuição de água em pivô central
}

\author{
Mateus Possebon Bortoluzzi, Marcelo Herter Mattioni
}

https://doi.org/10.4322/mp.978-65-991393-7-6.c2

\begin{abstract}
Resumo
A uniformidade de distribuição de água é influenciada pelo aspersor utilizado em sistemas de irrigação pivô central, sendo importante para evitar a ocorrência de excesso ou déficit hídrico para as culturas e aumentar a eficiência do uso da água. $O$ objetivo desse trabalho foi avaliar a uniformidade de distribuição de água de dois tipos de aspersores e a variabilidade de distribuição de água entre os lances do pivô central. Foram realizadas avaliações em duas áreas de lavoura comercial equipadas com sistema de irrigação do tipo pivô central, com aspersores do tipo Super Spray (Pivô 01) e I-Wob (Pivô 02). Foram aplicadas lâminas de irrigação de 5 e $13 \mathrm{~mm}$ nos Pivôs 01 e 02 , respectivamente, utilizando-se copos coletores para avaliação da distribuição de água. Os coletores foram alocados em duas linhas espaçados de $5 \mathrm{~m}$, totalizando 82 e 62 unidades no Pivô 01 e Pivô 02, respectivamente. Durante o experimento, foi realizada a medição da velocidade do vento, da temperatura e umidade relativa do ar através do Termo Higro Anemômetro Digital - KR825. A uniformidade da irrigação foi avaliada através do Coeficiente de Uniformidade de Christiansen (CUC) e do Coeficiente de Uniformidade de Distribuição (CUD). Os dados de lâmina coletada nos lances dos pivôs foram submetidos à análise de variância e teste Tukey. O modelo de aspersor I-Wob apresentou maiores coeficientes de uniformidade, proporcionando melhor uniformidade de distribuição de água. No Pivô equipado com aspersores Super Spray, a lâmina média aplicada foi de $4,04 \mathrm{~mm}$, inferior à lâmina programada e a uniformidade de distribuição de água foi semelhante ao longo do pivô. No Pivô equipado com aspersores I-Wob, a lâmina de água aplicada foi menor nos primeiros lances do pivô, maior nos lances intermediários e próximo à lâmina programada na extremidade do pivô.
\end{abstract}

Palavras-chave: coeficientes de uniformidade, eficiência da irrigação, irrigação por aspersão, I-Wob, super spray.

\section{Introdução}

A água é um componente fundamental do meio ambiente, a qual apresenta importância na geração de energia elétrica, navegação, abastecimento doméstico e industrial, bem como para irrigação de cultivos agrícolas [1]. Entretanto, tendo em vista o aumento da população, da demanda mundial por alimentos e a pequena disponibilidade de novas áreas para cultivo, torna-se cada vez mais importante 0 aumento da produtividade, porém de forma sustentável, principalmente em relação à eficiência do uso da água.

O Brasil possui uma área irrigada de aproximadamente sete milhões de hectares, sendo que aproximadamente $17 \%$ dessa área irrigada por sistema de irrigação do tipo pivô central [1]. No Rio Grande do Sul, esse sistema é utilizado dentre outras, para as 
culturas do milho, soja e feijão, totalizando 1285 equipamentos que irrigam uma área de 91.849 ha [2], propiciando estabilidade de produção e aumento de produtividade nessas áreas.

O sistema de irrigação do tipo pivô central é constituído por uma linha lateral de aspersão montada sobre um sistema de treliças e mantida a uma determinada altura do solo por torres de sustentação movimentadas por rodas ao redor de uma torre central ancorada [3]. Ao longo da linha lateral estão posicionados os aspersores, os quais apresentam fundamental importância para que a lâmina de água seja aplicada de forma igualitária em toda a área.

A uniformidade de distribuição de água é afetada por fatores meteorológicos, como a velocidade do vento, temperatura e umidade do ar [4] e por fatores relacionados ao equipamento, dentre os quais o tipo de aspersor. Os aspersores apresentam diferenças de uniformidade de aplicação de água, o que interfere, dentre outros fatores, na produtividade final, eficiência do uso do nitrogênio e eficiência do uso da água $[5,6]$.

Dentre os aspersores mais utilizados estão o Super Spray e o I-Wob, ambos fabricados pela empresa Senninger. O Super Spray opera com pressão de $20 \mathrm{PSI}$ (baixa pressão) e apresenta um padrão de pulverização de $360^{\circ}$. Possuem três formas de placas defletoras, as quais podem ser do tipo plana, côncava ou convexa e com superfície do tipo lisa, com ranhuras médias ou com ranhuras grossas, o que modifica o padrão de distribuição e o tamanho das gotas. O I-Wob, por sua vez, é um tipo de aspersor que opera com baixa (15 PSI) e ultra-baixa pressão (6-10 PSI). Possui mecanismo oscilante Wobbler e um disco defletor ranhurado, com modelos que proporcionam tamanhos de gotas diferentes.

Nesse sentido, devem-se priorizar aspersores que proporcionem adequada uniformidade de aplicação de água, evitando assim irrigações deficitárias ou em excesso. Dessa forma, evita-se perda de produtividade decorrente da falta de água, assim como por excesso hídrico, perda de solo e nutrientes ocasionados pelo escorrimento superficial decorrente da irrigação excessiva. De acordo com [7], houve maior produtividade de grãos do feijoeiro com a melhoria da uniformidade de aplicação da água.

A uniformidade de distribuição de água na superfície pode ser avaliada através de coeficientes de uniformidade, dentre os quais estão o Coeficiente de Uniformidade de Christiansen (CUC) e o Coeficiente de Uniformidade de Distribuição (CUD) [8]. Esses coeficientes vêm sendo bastante empregados para a avaliação da uniformidade de distribuição de água $[9,10]$. Cabe ressaltar que a distribuição de água no interior do perfil do solo é mais uniforme do que na superfície $(9,11)$, o que minimiza parcialmente os problemas ocasionados pela inadequada distribuição de água.

O objetivo desse trabalho foi avaliar a uniformidade de distribuição de água de dois tipos de aspersores utilizados em pivô central e a variabilidade de distribuição de água entre os lances dos equipamentos.

\section{Material e Métodos}

O experimento foi realizado na Fazenda Coqueiro, no município de São Luiz Gonzaga

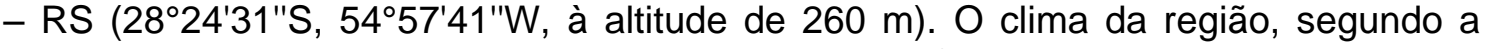
classificação de Köppen, é do tipo subtropical úmido (Cfa), sem estação seca definida [12]. O relevo do local é suavemente ondulado, em que o solo predominante é 
classificado como Latossolo Vermelho, pertencente à Unidade de Mapeamento Santo Ângelo [13].

Foram realizadas avaliações em duas áreas de lavoura comercial equipadas com sistema de irrigação do tipo pivô central e que na safra 2018/19 foram utilizadas com a cultura do milho. Os pivôs foram nomeados como Pivô 01 e Pivô 02, os quais possuem uma área irrigada de aproximadamente 52 e 30 ha, respectivamente. Ambos os equipamentos são da marca Valley.

O Pivô 01 é equipado com 186 aspersores de baixa pressão Super Spray (Senninger), a 2 metros do solo, com distância de 2,20 metros entre cada aspersor, o qual apresenta um padrão de pulverização de $360^{\circ}$. Possui placas defletoras côncavas (azuis), o que se traduz em um ângulo de 10ำ para maior distância e o tamanho de gotas é pequeno. A vazão dos aspersores varia de $61 \mathrm{I}^{-h^{-1}}$ a $6805 \mathrm{I}^{-h^{-1}}$ e não apresentam peças móveis.

O Pivô 02, por sua vez, possui 136 aspersores do tipo I-Wob (Senninger), que operam em ultra-baixa pressão. Os aspersores possuem placa com trajetória de ângulo padrão (pretas) com tamanho de gotas médias e apresentam vazão entre $182 \mathrm{I} . \mathrm{h}^{-1}$ e $4168 \mathrm{I} . \mathrm{h}^{-1}$. A tecnologia de oscilação (Wobbler) produz intensidade de aplicação baixa, o que auxilia na redução da desestruturação física do solo.

Foi realizada uma avaliação em ambas as áreas, em que foram aplicadas lâminas de irrigação de 5 e $13 \mathrm{~mm}$ nos Pivôs 01 e 02, respectivamente. A avaliação foi realizada utilizando copos coletores, da marca Fabrimar, apoiados em hastes com $50 \mathrm{~cm}$ de comprimento e com diâmetro e altura de $10 \mathrm{~cm}$. Os copos coletores foram alocados em duas linhas no sentido norte - sul dos pivôs centrais em um ângulo aproximado de $3^{\circ}$ entre elas (Figura 1). Em [14] ressalta-se a necessidade de pelo menos duas linhas de copos coletores, o que possibilita obter resultados semelhantes aos obtidos com o uso de quatro linhas. O espaçamento entre os copos coletores foi de $5 \mathrm{~m}$, totalizando 82 e 62 unidades no Pivô 01 e Pivô 02, respectivamente. Após a irrigação, a água coletada foi transferida para um copo medidor, onde foi feita a mensuração da altura armazenada em cada copo coletor.

Durante o experimento, foi realizada a medição da velocidade do vento e da temperatura do ar através do Termo Higro Anemômetro Digital - KR825, o qual apresenta resolução de $0,1^{\circ} \mathrm{C}$ e exatidão de $\pm 1^{\circ} \mathrm{C}$ para a temperatura do ar, resolução de $1 \%$ e exatidão de $\pm 5 \%$ para umidade relativa do ar e resolução de $0,1 \mathrm{~m}^{-1} \mathrm{~s}^{-1} \mathrm{e}$ exatidão de $\pm 5 \%$ para a velocidade do vento.

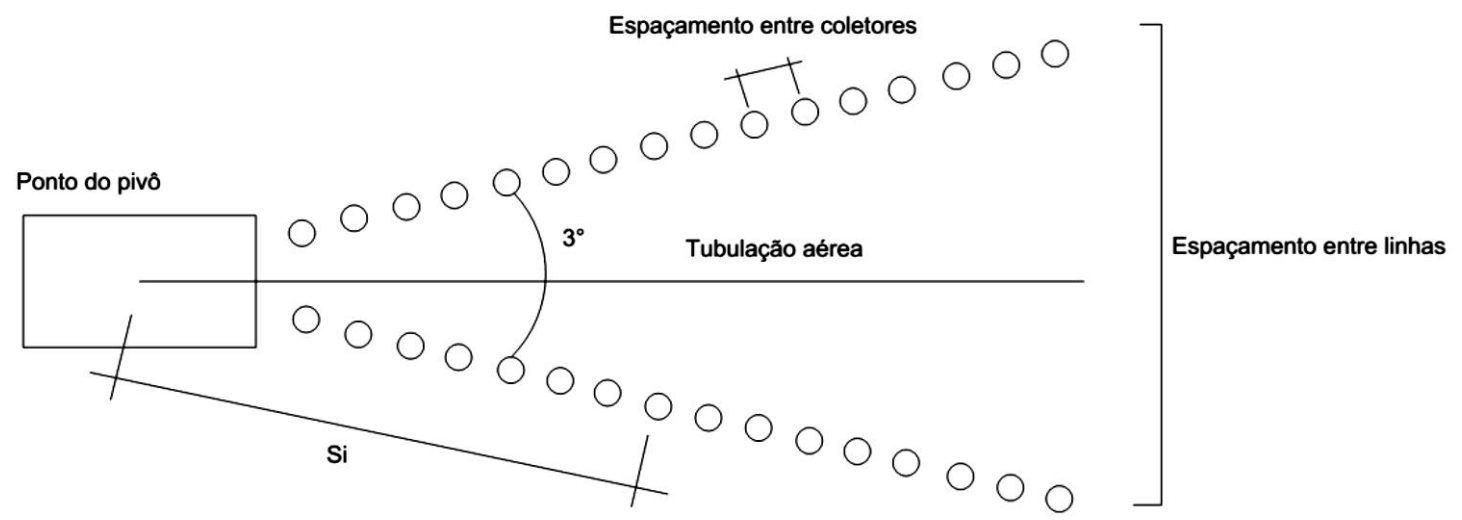

Figura 1. Distribuição dos copos coletores para a realização do teste de uniformidade de distribuição de água. 
A uniformidade da irrigação foi avaliada através do Coeficiente de Uniformidade de Christiansen (CUC), o qual é um índice estatístico que faz uso do desvio médio absoluto que expressa a dispersão das lâminas, conforme expresso na Equação 1 [8]. Os copos coletores foram numerados em ordem crescente a partir do centro do pivô, sendo essa numeração utilizada para a ponderação da lâmina de água armazenada nos copos coletores, tendo em vista que a área representada por cada copo coletor aumenta em direção à extremidade do pivô. A distribuição de água é classificada, pelo método do CUC, como ruim ( $<80 \%)$, regular (80 a $84 \%)$, bom (85 a $89 \%$ ), muito bom (>90\%).

$\mathrm{CUC}=100 \times\left(1-\left(\frac{\sum_{\mathrm{i}=1}^{\mathrm{n}}\left|\mathrm{Y}_{\mathrm{i}}-\overline{\mathrm{Y}}\right|}{\mathrm{n} \times \overline{\mathrm{Y}}}\right)\right)$

Em que:

CUC - Coeficiente de Uniformidade de Christiansen (\%);

Yi - Lâmina coletada no pluviômetro de ordem i $(\mathrm{mm})$;

$\mathrm{n}$ - Número de coletores;

$\mathrm{Y}=$ Lâmina média coletada $(\mathrm{mm})$.

O Coeficiente de Uniformidade de Distribuição (CUD) também foi utilizado, o qual relaciona a lâmina de água coletada na quarta parte dos coletores que receberam a menor quantidade de água com a lâmina média obtida em todos os coletores (Equação 2). O CUD é classificado como ruim (<70\%), regular (70 a $74 \%$ ), bom (75 a $81 \%$ ) e muito bom (>82\%) [8].

$\mathrm{CUC}=\left(\frac{\mathrm{X}_{25 \%}}{\overline{\mathrm{X}}}\right)$

(Equação 1)

Em que:

$\mathrm{X}_{25 \%}$ - Lâmina média de $25 \%$ dos coletores com menor lâmina coletada (mm);

$\mathrm{X}$ - Lâmina média coletada $(\mathrm{mm})$

Os dados de lâmina de água medida nas duas fileiras de copos coletores foram submetidos à análise de variância e teste de Tukey, a 5\% de probabilidade de erro, em que os lances que constituem o pivô central foram considerados como fonte de variação.

\section{Resultados e Discussão}

O modelo de aspersor I-Wob, utilizado no Pivô 02, foi o que proporcionou a melhor uniformidade de distribuição de água. Os valores de ambos os coeficientes de uniformidade foram superiores aos obtidos para o Pivô 01, em que foram utilizados os aspersores do modelo Super Spray (Tabela 1). O Coeficiente de Uniformidade de Christiansen (CUC) e o Coeficiente de Uniformidade de Distribuição (CUD) foram de $90,6 \%$ e $80,8 \%$ para o I-Wob e de $78,3 \%$ e $64,7 \%$ para o Super Spray, respectivamente (Tabela 1).

A uniformidade de distribuição foi classificada como muito boa (CUC) e boa (CUD) para o Pivô 02, equipado com aspersores do tipo I-Wob, sendo que os valores dos coeficientes obtidos foram superiores aos valores médios obtidos por [15] a partir da avaliação de 70 equipamentos nas regiões de Santo Augusto e Cruz Alta, RS. Já para o Pivô 01, equipado com aspersores do tipo Super Spray, o desempenho obtido para 
ambos os coeficientes foram classificados como ruim. No caso da cultura do milho, com o crescimento em altura a uniformidade de distribuição tende a diminuir, tendo em vista que quanto menor a altura do emissor em relação à superfície menor a área de recobrimento [14].

Tabela 1. Coeficiente de Uniformidade de Christiansen (CUC) e Coeficiente de Uniformidade de Distribuição (CUD) determinados para os Pivôs 01 e 02 , equipados com os aspersores Super Spray e I-Wob, respectivamente. São Luiz Gonzaga, RS.

\begin{tabular}{lcc}
\hline Pivô Central / Bico & CUC (\%) & CUD (\%) \\
\hline 01 (Super Spray) & 78,3 & 64,7 \\
02 (I-Wob) & 90,6 & 80,8 \\
\hline
\end{tabular}

A menor uniformidade de distribuição de água pode ocasionar redução de produtividade das culturas agrícolas, bem como reduzir a eficiência do uso da água. De acordo com [7], houve uma redução de 32,8\% da lâmina média a ser aplicada no ciclo do feijoeiro quando os valores de CUC passam de 65 para 90\%. Assim, maior uniformidade de distribuição de agua também está associada à redução do consumo de energia, bem como ao aumento da receita para o produtor [16].

A melhor uniformidade de distribuição de água no Pivô 02 está bastante relacionada às características de distribuição de água dos aspersores I-Wob, devido ao maior tamanho de gotas, o que reduz a influência do vento, assim como pelo próprio mecanismo de oscilação do aspersor proporcionando melhor distribuição de água. A baixa uniformidade de distribuição de água no Pivô 01 pode estar relacionada ao tamanho de gotas mais finas, potencializando a influência do vento, bem como fatores relacionados ao equipamento, como pressão de operação do emissor, velocidade e alinhamento da linha lateral do equipamento. Além disso, a substituição por novos aspersores e reguladores de pressão de mesmas características pode melhorar os valores de CUC [17]. Porém, faz-se importante avaliar a viabilidade econômica deste procedimento [18].

A lâmina de água medida a partir da coleta dos copos coletores apresentou variabilidade, assim como verificado por [4, 6, 17]. No Pivô 01, equipado com aspersores Super Spray, houve variabilidade elevada e semelhante ao longo de toda a extensão do pivô central, em que a lâmina de água medida nos diferentes copos coletores variou entre 1 e $6,25 \mathrm{~mm}$ (Figura 1A). Com relação ao Pivô 02, com aspersores I-Wob, os segmentos ao longo do pivô apresentaram diferente variabilidade de distribuição de água, com variação da lâmina medida nos copos coletores entre 9,5 e $17 \mathrm{~mm}$. Houve tendência de menor lâmina aplicada próximo ao centro do pivô, maior lâmina aplicada no quarto e quinto lance e lâmina mais uniforme e próxima à média no balanço e na área irrigada pelo canhão final na extremidade do pivô central (Figura 1B).

De acordo com a análise de variância realizada, verificou-se diferença significativa entre a altura da lâmina irrigada medida nos diferentes lances de ambos os equipamentos. A lâmina média de água coletada no Pivô 01 foi de 4,04 mm (Tabela 2), sendo inferior à lâmina calibrada de $5 \mathrm{~mm}$, o que pode estar relacionado a diferença da velocidade de deslocamento no campo com a indicada no relé percentual ou bocais com vazão inadequada ao longo do pivô. 

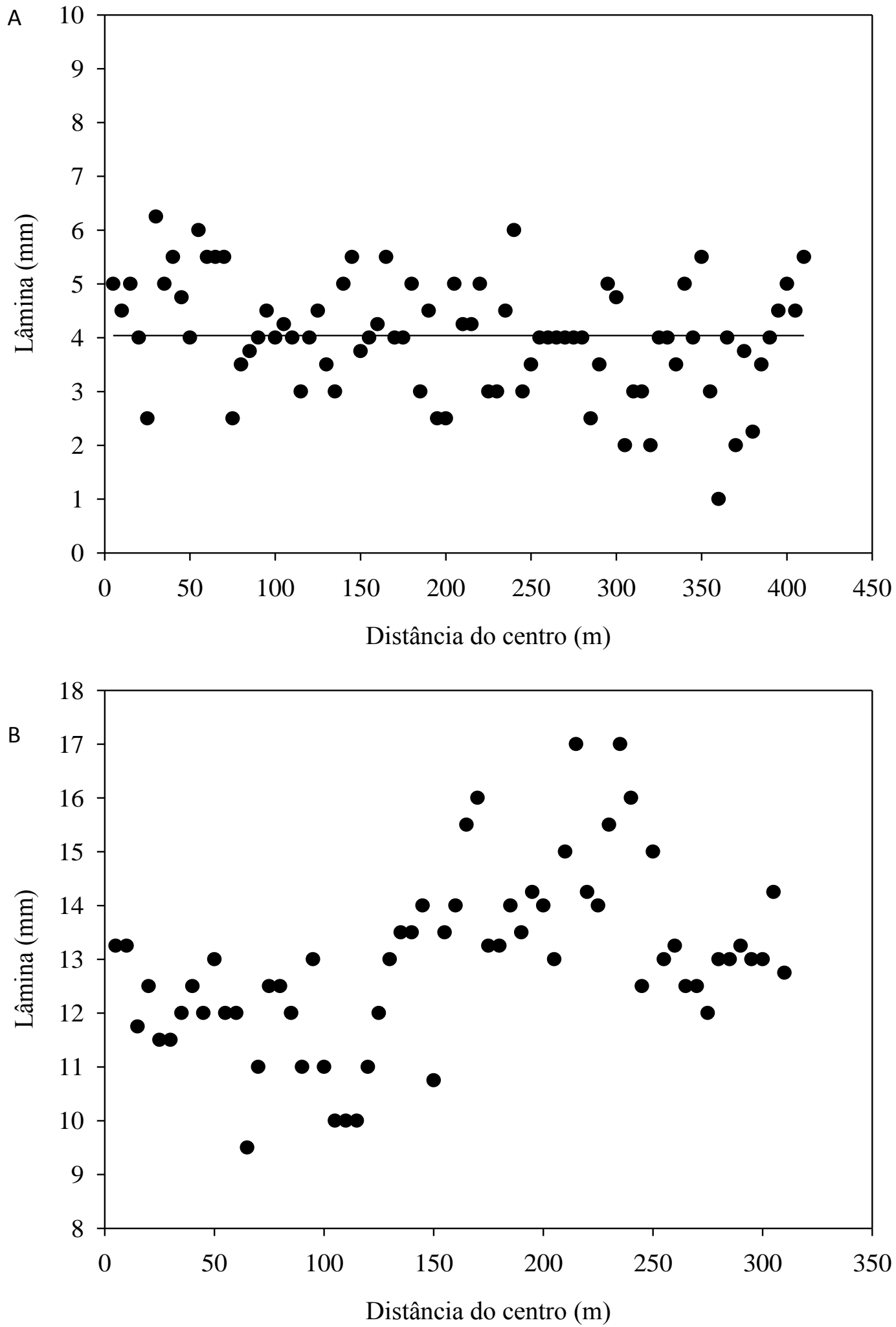

Figura 1. Lâmina média coletada (linha sólida) e lâmina medida em copos coletores ao longo dos equipamentos do tipo pivô central, equipados com aspersores modelo Super Spray (A) e I-Wob (B). São Luiz Gonzaga, RS.

Já para o Pivô 02, a lâmina coletada foi de $12,95 \mathrm{~mm}$, a qual ficou bem próxima da lâmina de $13 \mathrm{~mm}$, regulada no painel de controle do pivô central (Tabela 2). Também se pode inferir que a variabilidade das lâminas coletadas foi maior no Pivô $01 \mathrm{em}$ 
relação ao Pivô 02, tendo em vista os maiores valores de coeficiente de variação (CV) obtidos

Tabela 2. Lâmina $(\mathrm{mm})$ de água obtida em nove lances de um pivô central equipado com aspersores do tipo Super Spray, e em sete lances de um pivô central equipado com aspersores do tipo I-Wob. São Luiz Gonzaga, RS.

\begin{tabular}{cr}
\hline Lances & Lâmina $(\mathrm{mm})$ \\
\hline Pivô 01 (Super Spray) \\
\hline 1 & $4,65 \mathrm{a}$ \\
2 & $4,47 \mathrm{a}$ \\
3 & $4,47 \mathrm{a}$ \\
4 & $3,92 \mathrm{a}$ \\
5 & $4,15 \mathrm{a}$ \\
6 & $3,97 \mathrm{a}$ \\
7 & $3,60 \mathrm{ab}$ \\
8 & $2,66 \mathrm{~b}$ \\
9 & $4,50 \mathrm{a}$ \\
\hline Média & 4,04 \\
CV (\%) & 24,56 \\
\hline \multicolumn{1}{c}{ Pivô 02 (I-Wob) } \\
\hline 2 & $12,32 \mathrm{~cd}$ \\
3 & $11,65 \mathrm{~d}$ \\
4 & $11,77 \mathrm{~d}$ \\
5 & $14,12 \mathrm{ab}$ \\
6 & $14,92 \mathrm{a}$ \\
7 & $12,70 \mathrm{~cd}$ \\
Média & $13,20 \mathrm{bc}$ \\
CV (\%) & 12,95 \\
\end{tabular}

Considerando a lâmina de água média obtida em cada lance do Pivô 01, verificou-se que em todos os lances a lâmina aplicada foi menor do que a programada (Tabela 2). No primeiro lance do Pivô 01 a lâmina medida $(4,65 \mathrm{~mm})$ foi a que mais se aproximou da lâmina programada, sendo que para o lance 8 (balanço), a lâmina aplicada foi praticamente a metade da programada (Tabela 3), o que pode reduzir a produtividade das culturas principalmente nesta área de abrangência do pivô central devido aos possíveis efeitos do déficit hídrico.

A mesma tendência obtida na Figura 1B para o Pivô 02 pode ser observada na Tabela 2 , em que no balanço (lance 6) e no canhão final (lance 7) foram obtidos os valores mais próximos da lâmina de irrigação programada $(13 \mathrm{~mm})$. Além disso, houve maior e menor lâmina medida nos lances 4 e 5 e nos três primeiros lances, respectivamente. Isso pode estar relacionado a bocais com vazão diferente da considerada adequada em algum intervalo do pivô, emissores total ou parcialmente obstruídos ou danificados, vazamentos nos flanges, assim como reguladores de pressão danificados resultando em pressões diferentes das especificadas em projeto [19]. Por consequência, ao realizar a irrigação, parte da área é irrigada em excesso, enquanto que em outra fração ocorre déficit hídrico [20].

Durante a avaliação no Pivô 01 , a temperatura do ar e a velocidade do vento variaram entre 27,3 e $28^{\circ} \mathrm{C}$ e 2,5 e $13,6 \mathrm{~km} / \mathrm{h}$, enquanto na avaliação do Pivô 02 variaram entre 
35,6 e $35,9^{\circ} \mathrm{C}$ e 2,4 a $12,6 \mathrm{~km} / \mathrm{h}$, respectivamente (Tabela 3). A umidade relativa do ar medida foi de $35 \%$ no Pivô 01 e $25 \%$ no Pivô 02. Esses valores dos elementos meteorológicos indicam um ambiente com potencial evaporativo acentuado das gotas provenientes da irrigação. As variações dos valores de velocidade do vento indicam que houve alguns picos de vento durante a aplicação, o que pode ter influenciado na distribuição de água [4].

Tabela 3. Temperatura do ar $\left({ }^{\circ} \mathrm{C}\right)$, velocidade do vento $(\mathrm{km} / \mathrm{h})$ mínima e máxima e umidade relativa do ar (\%) medidas durante a irrigação realizada nas duas linhas de copos coletores no Pivô 01, equipado com aspersores do tipo Super Spray e no Pivô 02, equipado com aspersores do tipo I-Wob. São Luiz Gonzaga, RS.

\begin{tabular}{|c|c|c|c|c|c|}
\hline \multirow[t]{2}{*}{ Pivô Central } & \multirow{2}{*}{$\begin{array}{c}\text { Linha } \\
\text { coletores }\end{array}$} & \multirow{2}{*}{$\begin{array}{c}\text { Temperatura } \\
\text { do } \operatorname{ar}\left({ }^{\circ} \mathrm{C}\right)\end{array}$} & \multicolumn{2}{|c|}{$\begin{array}{l}\text { Velocidade do vento } \\
\qquad(\mathrm{km} / \mathrm{h})\end{array}$} & \multirow{2}{*}{$\begin{array}{c}\text { Umidade } \\
\text { relativa do ar } \\
(\%)\end{array}$} \\
\hline & & & Mínima & Máxima & \\
\hline $\begin{array}{c}01 \\
\text { (Super }\end{array}$ & 1 & 27,3 & 2,8 & 13,6 & 35 \\
\hline Spray) & 2 & 28,0 & 2,5 & 11,8 & 35 \\
\hline 02 & 1 & 35,6 & 2,8 & 10,4 & 25 \\
\hline (I-Wob) & 2 & 35,9 & 2,4 & 12,6 & 25 \\
\hline
\end{tabular}

\section{Conclusão}

O modelo de aspersor I-Wob foi o que apresentou maiores valores dos coeficientes de uniformidade, proporcionando melhor uniformidade de distribuição de água.

No Pivô equipado com aspersores Super Spray, a lâmina aplicada foi menor que a programada e a uniformidade de distribuição de água foi semelhante ao longo do pivô.

No Pivô equipado com aspersores I-Wob, a lâmina de água aplicada foi inferior à lâmina média nos primeiros lances do pivô, maior nos lances intermediários e próximo à lâmina programada na extremidade do pivô.

\section{Referências}

[1] Agência Nacional de Águas. Atlas Irrigação: Uso da Água na Agricultura Irrigada. Brasília: $\quad$ ANA; $2017 . \quad 86 \quad$ p. $\quad$ Disponível em: $<$ https://arquivos.ana.gov.br/imprensa/publicacoes/AtlaslrrigacaoUsodaAguanaAgriculturalrrigada.pdf>. Acesso em: 16 Jan. 2021.

[2] Manke, E.B., Faria, L.C., Pereira, M.G. Nörenberg, B.G., Caldeira, T.L., Oliveira, H.F. Identificação de áreas irrigadas por pivô central e linear móvel no estado do Rio Grande do Sul. Irriga, 2017; 22:343-352. https://doi.org/10.15809/irriga.2017v22n2p343-352. 
[3] Testezlaf, R. Irrigação: Métodos, sistemas e aplicações. 1. ed. Campinas: Unicamp/FEAGRI, 2017. 215p. Disponível em: <https://www.feagri.unicamp.br/irrigacao/livros>. Acesso em: 16 Jan. 2021.

[4] Evangelista, W., Oliveira, C.A.S., Silva, C.L. Variáveis climáticas e o desempenho de um pivô central, em Cristalina Goiás. Revista Brasileira de Engenharia Agrícola e Ambiental, 2010; 14:246-252. http://dx.doi.org/10.1590/S1415-43662010000300002.

[5] Jiao, J., Wang, Y., Han, L., Su, D. Comparison of Water Distribution Characteristics for Two Kinds of Sprinklers Used for Center Pivot Irrigation Systems. Applied Sciences, 2017; 7:1-17. https://doi.org/10.3390/app7040421.

[6] Cai, D.Y., Yan, H.J., Li L.H. Effects of water application uniformity using a center pivot on winter wheat yield, water and nitrogen use efficiency in the North China Plain. Journal of Integrative Agriculture, 2020; 19: 2326-2339. https://doi.org/10.1016/S20953119(19)62877-7.

[7] Mantovani, E.C., Montes, David R.P., Vieira, G.H.S., Ramos, M.M., Soares, A.A. Estimativa de produtividade da cultura do feijão irrigado em Cristalina-GO, para diferentes lâminas de irrigação como função da uniformidade de aplicação. Engenharia Agrícola, 2012; 32;110-120. http://dx.doi.org/10.1590/S0100-69162012000100012.

[8] Bernardo, S., Soares, A.A., Mantovani, E.C., Silva, D.D. Manual de irrigação. 9. ed. Viçosa: Universidade Federal de Viçosa, 2019. 545 p.

[9] Rodrigues, T.R.I., Batista, H.S., Carvalho, J.M., Gonçalves, A.O., Matsura, E.E. Uniformidade de distribuição de água em pivô central, com a utilização da técnica TDR na superfície e no interior do solo. Revista Brasileira de Engenharia Agrícola e Ambiental, 2001; 5:187-191. http://dx.doi.org/10.1590/S1415-43662001000200002.

[10] Nascimento, V.F., Feitosa, E.O., Soares, J.I. Uniformidade de distribuição de um sistema de irrigação por aspersão via pivô central. Revista de Agricultura Neotropical, 2017; 4;65-69. http://dx.doi.org/10.32404/rean.v4i4.1643.

[11] Rezende, R., Frizzone, J.A., Gonçalves, A.C.A., Freitas, P.S.L. Influência do espaçamento entre aspersores na uniformidade de distribuição de água acima e abaixo da superfície do solo. Revista Brasileira de Engenharia Agrícola e Ambiental, 1998; 2;257-261. http://dx.doi.org/10.1590/1807-1929/agriambi.v2n3p257-261.

[12] Kuinchtner, A., Buriol, G. A. Clima do Estado do Rio Grande do Sul segundo a classificação climática de Köppen e Thornthwaite. Disciplinarum Scientia, 2001; 2;171182. https://doi.org/10.37779/nt.v2i1.1136.

[13] Streck, E.V., Kämpf, N., Dalmolin, R.S.D., Klamt, E., Nascimento, P.C. do, Schneider, P., Giasson, E., Pinto, L.F.S. Solos do Rio Grande do Sul. 2. ed. Porto Alegre: EMATER/RS-ASCAR, 2008. 222 p.

[14] Heinemann, A.B., Frizzone, J.A., Pinto, J.M., Filho, J.C.F. Influência da altura do emissor na uniformidade de distribuição da água de um sistema de pivô central. Pesquisa Agropecuária Brasileira, 1998; 33:1487-1491. Disponível em: <https://www.embrapa.br/busca-de-publicacoes/-/publicacao/132264/influencia-daaltura-do-emissor-na-uniformidade-de-distribuicao-da-agua-de-um-sistema-pivocentral>. Acesso em 16 Jan. 2021. 
[15] Schons, R.L.; Robaina, A.D., Peiter, M.X. Caracterização e avaliação de áreas irrigadas no Rio Grande do Sul. Tecnologia \& Ciência Agropecuária, 2014; 8;55-59. Disponível em: <https://revistatca.pb.gov.br/edicoes/volume-08-2014/volume-8numero-1-marco-2014/tca8110.pdf>. Acesso em: 16 Jan. 2021.

[16] Mendoza, C.J.C., Frizzone, J.A. Economia de energia em irrigação por pivô central em função da melhoria na uniformidade da distribuição de água. Revista Brasileira de Agricultura Irrigada. 2012; 6;184-197. https://doi.org/10.7127/rbai.v6n300083.

[17] Klar, A.E., Santana, R.C., Duroha, C. Evaluation center pivot systems using new and old sprays and pressure regulators. Irriga, 2001; 06;42-47. https://doi.org/10.15809/irriga.2001v6n1p42-47.

[18] Zolin, C.A., Coelho, R.D., Paulino, J., Folegatti, M.V. Economic viability of retrofiting emitters in center pivot irrigation systems. Engenharia Agrícola, 2012; 32;602-608. http://dx.doi.org/10.1590/S0100-69162012000300019.

[19] Sandri, D., Cortez, D.A. Parâmetros de desempenho de dezesseis equipamentos de irrigação por pivô central. Ciência e Agrotecnologia, 2009; 33(1):271-278. http://dx.doi.org/10.1590/S1413-70542009000100037.

[20] Lima, A.S., Zocoler, J.L. Uniformidade de distribuição e lâmina de água aplicada em sistema pivô central em função da posição relativa da linha lateral. Revista Pesquisa Aplicada \& Agrotecnologia, 2010; 3;27-32. Disponível em: $<$ https://revistas.unicentro.br/index.php/repaa/article/download/630/804>. Acesso em: 16 Jan. 2021.

\section{Autores}

Mateus Possebon Bortoluzzi*, Marcelo Herter Mattioni

Faculdade de Agronomia e Medicina Veterinária, Universidade de Passo Fundo, BR 285, São José, 99052-900, Passo Fundo, Brasil.

\footnotetext{
*Autor para correspondência: mateusbortoluzzi@upf.br
} 